\title{
EDITORIAL
}

\section{Is Public Health System in LMICs Ready to Respond to the Ever Growing NCDs?}

\author{
Abraham Haileamlak, MD, Professor of Pediatrics and Child Health \\ DOI: http://dx.doi.org/10.4314/ejhs.v25i3.1
}

Because of the urbanization, demographic transition and influence of globalization, the lifestyle of people in many of the low and middle income countries (LMIC) is changing; heading to unhealthy dietary habit, physical inactivity and use of cigarette and alcohol. The lifestyle changes on the background of earlier malnutrition, inevitably leads to central obesity. This with the stressful situation caused by the competitive environment catalyzes the surge of Non Communicable Diseases (NCDs).

Reports showed that the burden of NCDs in LMICs is on the rise. As a result, NCDs are responsible for two-thirds of the world's deaths$80 \%$ in low- and middle-income countries. In subSaharan Africa, NCDs contribute a third of the disability-adjusted life year burden.

However, resources allocated to prevent and treat NCDs in LMICs are none or little (1). Until recently, communicable diseases remained the sole priority for health policy though they do not constitute the major contributor to the burden of disease in terms of disability-adjusted life years or mortality in any region of the world apart from sub-Saharan Africa $(2,3)$.

Though essential to reduce the future disease burden, prevention interventions will do little for those people who have already developed NCDs, and who are essentially being used to validate investments that will come too late to help them. While working on limiting the number of future NCD patients, an important duty is to ensure that people with NCDs receive quality care today.

Investing to improve primary care to shoulder NCD services- the main entry point to health services for most people in resource-limited settings - has the potential to overcome some of these problems (4). From the successful experience gained in delivering interventions for communicable diseases such as HIV, tuberculosis and malaria, Sub-Saharan African countries should capacitate and utilize primary care centers on prevention, identification and follow-up of NCDs. Some Sub-Saharan African countries like Rwanda have started exemplary integrated NCDs services at all levels of care which others need to benchmark.

Since the tertiary centers are not ready to care the deadly and disabling NCDs, concurrent development tertiary centers to provide emergency and subsequent intervention should be developed to handle the prevalent and emerging cases.

The current issue (Vol. 25, No 3), the third issue of the 25th year anniversary of EJHS contains ten original articles on varied subjects and three case reports focusing on different areas. I invite readers to read through these articles and appreciate or utilize the contents. I also encourage readers to forward comments and suggestions.

\section{REFERENCES}

1. Beaglehole R, Ebrahim S, Reddy S, et al. (2007) Prevention of chronic diseases: a call to action. Lancet 307: 2152-2157. d

2. Ollila E. Global health priorities - priorities of the wealthy? Global Health.2005; 1:6.

3. Gaziano TA, Reddy KS, Paccaud F, Horton S, Chaturvedi V. Cardiovascular disease. In: JAMISON DT, BREMAN JG, MEASHAM AR, et al., editors. Disease Control Priorities in Developing Countries. 2nd edn. Oxford University Press; New York: 2006.

4. Chan M. Historical agreements at the Sixtyfourth World Health Assembly. In: Sixtyfourth World Health Assembly, Geneva, Switzerland, 16-24 May 2011. Available at: http://www.who.int/dg/speeches/2011/wha_2 0110524/en/index.html [accessed June 2015]. 